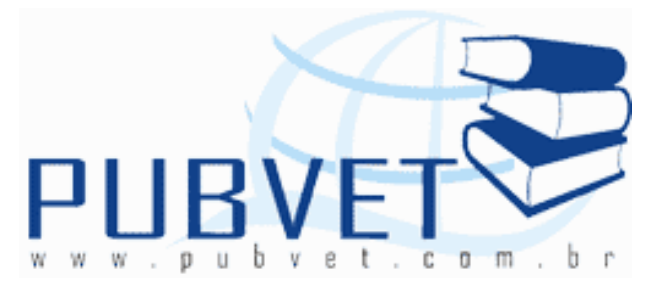

PUBVET, Publicações em Medicina Veterinária e Zootecnia.

\title{
Reflexão sobre o senso de percepção de risco no uso de agrotóxicos pelos pequenos agricultores no Assentamento Samba no Município de Maragogi - Alagoas
}

\author{
Paulo Sérgio Lins da Silva ${ }^{1}$, Jakes Halan de Queiroz Costa ${ }^{2}$, Ailton Silva \\ Galvão ${ }^{3}$, Tania Marta Carvalho dos Santos ${ }^{4}$
}

${ }^{1}$ Universidade Federal de Alagoas, Agronomo, UFAL BR 104 NORTE 85 - MATA DO ROLO - 57100 - 000 - Rio Largo, AL - Brasil E - mail: pslins@oi.com.br ${ }^{2}$ Prof . MSc UFAL E - mail: jakes@ceca.ufal.br ${ }^{3}$ Prof. MsC. UFAL E - mail: galvão@ig.com.br ${ }^{4}$ Profa. Dra. UFAL E - mail: tmcs@ceca.ufal.br

Trabalho de Conclusão de Curso do 10 Autor

\section{Resumo}

A proposição deste estudo é realizar uma reflexão sobre o senso de percepção de risco no uso de agrotóxicos pelos pequenos agricultores do Assentamento Samba no Município de Maragogi - Alagoas. A pesquisa de campo gerou dados originários de entrevistas que envolveram trinta agricultores familiares buscando-se conhecer a percepção de risco no uso e manuseio de agrotóxicos em suas atividades rurais. Os resultados indicaram que as orientações técnicas são de extrema importância para os agricultores e que métodos alternativos são de grande importância e de fácil aceitação pelos produtores rurais do Assentamento Samba, em oposição ao uso de agrotóxicos.

Palavras-chave: Percepção de risco, agrotóxicos, Assentamento Samba. 


\title{
Reflection on the sense of risk perception on pesticide use by smallholders in the Samba settlement in the municipality of Maragogi - \\ Alagoas
}

\begin{abstract}
The purpose of this study is a reflection on the sense of perceived risk in the use of pesticides by small farmers of the settlement in the municipality of Samba Maragogi - Alagoas. The field search has generated data originating of interviews involving thirty farmers seeking to know the perception of risk in the use and handling of pesticides in their rural activities. The results indicated that the guidelines are very important for farmers and that alternative methods are of great importance and easy acceptance by farmers of the settlement Samba, as opposed to the use of pesticides.
\end{abstract}

Keywords: Risk perception, pesticides, Settlement Samba.

\section{INTRODUÇÃO}

A exposição humana a agrotóxicos se constitui em grave problema de saúde pública em todo o mundo, principalmente nos países em desenvolvimento (KOH D, 1996, KONRADSON, 2003). Em 2005, 5.577 casos de intoxicação por agrotóxicos de uso agrícola foram notificados no Brasil, números que podem estar subestimados considerando-se a elevada subnotificação desses eventos no País (OLIVEIRA SILVA, 2003).

Numa revisão de 17 estudos conduzidos entre 1982 e 1999 em vários países, Keifer (2000) concluiu que a mudança nos procedimentos de aplicação e mistura, o uso de equipamentos de proteção individual (EPI) e o monitoramento biológico podem efetivamente diminuir a exposição ocupacional a agrotóxicos. Este debate começou a tomar significativas proporções fundamentalmente a partir das denúncias apresentadas por Rachel Carson, em 1962, no seu livro "A primavera silenciosa".

Cabe salientar que as intoxicações por exposição aos agrotóxicos resultam de uma interação complexa entre as características do agrotóxico e 
SILVA, P.S.L. et al. Reflexão sobre o senso de percepção de risco no uso de agrotóxicos pelos pequenos agricultores no Assentamento Samba no município de Maragogi - Alagoas. PUBVET, Londrina, V. 5, N. 11, Ed. 158, Art. 1068, 2011.

as características da exposição do trabalhador ao produto, incluindo a adoção de medidas e equipamentos de proteção (PERES, 2003).

Estudos promovidos por Levigard (2001) demonstram que a utilização de medidas e equipamentos de proteção não é uma conseqüência direta do conhecimento dos riscos associados ao manejo do agrotóxico, mas depende da maneira como, individual e coletivamente, os trabalhadores percebem o risco no uso destes produtos tóxicos.

Trabalho de Kouabena (2002) e Wejnert (2002) sugerem que o risco só adquire significado em oposição a outros elementos que intervêm na sua construção e a partir da sua relação com o contexto cultural. O mais importante, então, não seria o risco em si, mas sim as percepções da situação de risco, as quais envolvem interpretações, avaliações e julgamentos em dois níveis, o subjetivo e o intersubjetivo.

Para compreender melhor os fatores que determinam as práticas no uso de agrotóxicos, estudos têm sido conduzidos em populações rurais no Brasil e no mundo para avaliar o nível de conhecimento, as crenças e as percepções dos trabalhadores rurais sobre o risco da exposição a esses produtos (RECENA MC, 2006; TUCKER M, 2001). Em estudo realizado sobre o Brasil, Peres et al. (2005), enfatizaram a importância dos estudos de percepção de risco no processo de construção de estratégias de intervenção no meio rural, campanhas educativas e de comunicação de riscos.

As indústrias de agrotóxicos e grupos de cientistas tendem a argumentar que os riscos decorrem de um mal uso dos insumos de parte dos agricultores e se aqueles fossem utilizados de uma forma recomendada e imaginada correta, afirmam que os riscos desapareceriam. Entretanto, a comunidade científica aparece dividida sobre o caráter dos riscos e as condições que os produzem. Dentro de diversas áreas, como biologia, química, agronomia, botânica, ecologia e medicina, alguns pesquisadores preferem afirmar que os perigos tendem a ser exagerados, infundados e divulgados de forma sensacionalista, porque os dados são limitados (SWEET et al., 1990). 
SILVA, P.S.L. et al. Reflexão sobre o senso de percepção de risco no uso de agrotóxicos pelos pequenos agricultores no Assentamento Samba no município de Maragogi - Alagoas. PUBVET, Londrina, V. 5, N. 11, Ed. 158, Art. 1068, 2011.

Mas esta mesma limitação das conclusões leva a outros pesquisadores a afirmar que o desconhecimento não é sinônimo de inocuidade dos agrotóxicos e, até que os riscos decorrentes da agricultura moderna não sejam plenamente demonstrados, devem ser tomadas todas as precauções possíveis (NATIONAL RESEARCH COUNCIL, 1989; GAO，1990; DINHAM，1993). Alguns cientistas consideram que para certos perigos, como o câncer, qualquer nível de exposição pode ser de risco, não existindo a possibilidade de definir uma separação entre níveis seguros e inseguros de exposição (MOTT; SNYDER, 1987: 16).

O presente estudo teve por objetivo avaliar a percepção de risco, práticas e atitudes no uso de agrotóxicos pelos agricultores do Assentamento "Samba", localizado na zona rural do município de Maragogi, Estado de Alagoas.

\section{REVISÃO DE LITERATURA}

O conceito de risco mais amplamente utilizado se aproxima a um perigo mais ou menos definido (PERES, 2002) ou a probabilidade de perigo, geralmente com ameaça física para o homem e/ou para o ambiente (HOUAISS, 2001). Sua acepção mais fortemente aceita na literatura que trata dos problemas delimitados pelos campos da saúde, trabalho e ambiente é a composição de pelo menos dois dos três seguintes componentes (YATES, 1992): a) potencial de perdas e danos; b) a incerteza da perda/dano; e/ou c) a relevância da perda/dano.

Há, entretanto, um elemento comum a estes componentes: a distinção entre realidade e possibilidade. Segundo Slovic (1999), não há risco real, ou seja, o risco não existe enquanto realidade independente de nossas mentes e culturas. Ele só é possível de ser observado e mensurado dentro de um contexto. Em trabalhos realizados nas últimas décadas, Douglas (1982) e Slovic (1999) reconhecem o risco e as respostas ao risco como construtos sociais. 
SILVA, P.S.L. et al. Reflexão sobre o senso de percepção de risco no uso de agrotóxicos pelos pequenos agricultores no Assentamento Samba no município de Maragogi - Alagoas. PUBVET, Londrina, V. 5, N. 11, Ed. 158, Art. 1068, 2011.

As teorias das probabilidades de risco são criações mentais e sociais definidas em termos de graus de crença (SMITHSON, 1989). Slovic (1999) adota esta perspectiva e estabelece uma distinção entre a probabilidade de risco e a percepção do risco, partindo do ponto de vista de que risco "real" e risco percebido são duas dimensões diferentes. Esse autor reconhece que a equação risco/resposta ao risco é mediada por valores, tornando claro que outros fatores, além de uma avaliação técnica do risco, são nitidamente importantes para a compreensão de como as pessoas percebem e respondem aos riscos.

De acordo com Wejnert (1996), três aspectos da realidade atuam como mediadores entre a percepção do risco e o comportamento - as características individuais e socioculturais e as características das práticas. Outros autores como Wolpert (1996) e Lion et al. (2002) acrescentam que a discrepância entre a percepção do risco e o comportamento do indivíduo ou da coletividade pode estar também relacionada ao sentimento de controle sobre a realidade percebida. Com relação a este aspecto, Finuccane et al. (2000) afirmam que novos riscos tendem a ser percebidos como mais perigosos que riscos familiares.

O risco já foi abordado de diversas maneiras e por diversos autores. Destacamos entre elas a abordagem psicométrica do risco (SLOVIC, 2000) e as abordagens culturais e sociais (DOUGLAS, 1992). Estas abordagens têm em comum a noção de que os seres humanos percebem o mundo através de um filtro de valores e nelas a busca de significados emerge como sendo a dimensão central da pesquisa.

Horlick-Jones et al. (2003) pontuam que o papel central do significado e da interpretação na estruturação das interações sociais tem servido de base para outros estudos sobre o risco que se apóiam nas tradições hermenêutica e fenomenológica. Tais estudos, utilizando abordagens qualitativas ou mistas, têm o objetivo comum de obter o que Geertz (1973) descreveu como descrições densas das circunstâncias, nas quais o risco pode ser identificado e compreendido. 
SILVA, P.S.L. et al. Reflexão sobre o senso de percepção de risco no uso de agrotóxicos pelos pequenos agricultores no Assentamento Samba no município de Maragogi - Alagoas. PUBVET, Londrina, V. 5, N. 11, Ed. 158, Art. 1068, 2011.

Vários trabalhos produzidos dentro desta tradição (CORIN, 1992, UCHÔA, 2002, FIRMO, 2004, LOYOLA FILHO, 2004) mostram a influência dos universos social e cultural sobre a adoção de comportamentos de prevenção ou de risco. Nessa perspectiva, os comportamentos são associados às representações, as quais se formam na interação entre pessoas, diferindo de uma simples perspectiva cognitiva (STJERNA, 2004). Estas representações são mediadas por um complexo cultural que influencia a maneira pela qual os indivíduos percebem o risco, podendo levá-los a ações específicas, entre as quais a de ignorar sua probabilidade de ocorrência (DOUGLAS, 1985).

Conforme entendimento já apresentado, os agrotóxicos são substâncias que, apesar de serem cada vez mais utilizadas na agricultura, podem oferecer perigo para o homem, dependendo da toxicidade, do grau de contaminação e do tempo de exposição durante sua aplicação.

Igbedioh (1991), em seu estudo, relata que a exposição aos agrotóxicos por longo tempo em homens, plantas e animais tem efeitos nocivos e indesejáveis. Aponta como medidas para redução de riscos na sua utilização: a educação e treinamento dos agricultores, a regulação da propaganda, a limitação do uso de substâncias altamente tóxicas, o monitoramento da população mais exposta ao agrotóxico e a inspeção dos produtos nas lojas de venda e no campo.

Segundo Trapé (1993), ocorreram no mundo cerca de três milhões de intoxicações agudas por agrotóxicos, com 220 mil mortes por ano. Destas, cerca de $70 \%$ se dão em países do chamado Terceiro Mundo. Além da intoxicação dos trabalhadores que têm contato direto ou indireto com esses produtos, a contaminação de alimentos tem causado intoxicações e mortes.

No Brasil, um fator se destaca na análise das informações sobre intoxicações e envenenamentos no meio rural - a distância, que dificulta o acesso dos trabalhadores aos centros de atendimento médico-hospitalar. Essa situação faz com que inúmeras vítimas de acidentes graves acabem morrendo sem qualquer assistência médica. Os acidentes mais leves acabam freqüentemente não sendo sequer comunicados ao FUNRURAL (Fundação de 
SILVA, P.S.L. et al. Reflexão sobre o senso de percepção de risco no uso de agrotóxicos pelos pequenos agricultores no Assentamento Samba no município de Maragogi - Alagoas. PUBVET, Londrina, V. 5, N. 11, Ed. 158, Art. 1068, 2011.

Previdência ao Trabalhador Rural). Este fator é relevante para explicar a baixa incidência, apenas aparente, de acidentes leves entre os trabalhadores rurais (BORTOLETTO, 1990).

Outro fator a ser considerado na análise do sub-registro é a gravidade. Muitas vezes, as intoxicações por defensivos não são graves a ponto de exigir internação; e são freqüentes os casos em que os trabalhadores rurais, embora com sintomas de intoxicação, continuam sua jornada de trabalho sem procurar atendimento médico. Mesmo para casos de intoxicações graves, a falta de atendimento médico é causa comum de subregistro.

A informação e a notificação de intoxicações agudas produzidas por agrotóxicos continuam sendo deficientes no país devido à precária assistência médica na área rural e à semelhança dos sintomas de intoxicação por agrotóxicos com os de outras doenças, segundo o Ministério da Saúde (1997).

Dados oficiais recentes colocam o Brasil como o 70 consumidor mais freqüente no mundo, tendo sido consumidos no país, em 2001, 328.413 toneladas destes produtos (ANVISA, 2002).

Rozemberg (1994) realizou um estudo sobre o consumo de calmantes e os chamados "problemas de nervos" entre 93 lavradores, em 25 comunidades rurais da região serrana do Estado do Espírito Santo. Constatou que 30\% dos lavradores entrevistados se diziam com "problemas de nervos" e os principais sinais e sintomas descritos eram: tonteira e tremores, insônia, fraqueza e cansaço. Sintomas semelhantes aos encontrados nas intoxicações por inseticidas organofosforados.

Uma pesquisa realizada pela Secretaria de Agricultura do Estado do Paraná (SIQUEIRA et al., 1983) mostrou que, no período de agosto de 1982 a março de 1983, ocorreram cerca de 1.500 casos de intoxicações por agrotóxicos naquele Estado, dos quais 1.268 (84,5\%) na cultura de algodão. A faixa etária entre 20 e 30 anos foi a que apresentou o maior número de intoxicações. Outro dado importante se refere às tentativas de suicídio por ingestão de agrotóxicos, muito comuns no meio rural. De 41 casos constatados, 24 foram de óbito, representando $1,5 \%$ do total das pessoas 
SILVA, P.S.L. et al. Reflexão sobre o senso de percepção de risco no uso de agrotóxicos pelos pequenos agricultores no Assentamento Samba no município de Maragogi - Alagoas. PUBVET, Londrina, V. 5, N. 11, Ed. 158, Art. 1068, 2011.

intoxicadas. Também foi constatada a permanência de resíduos de agrotóxicos nos alimentos produzidos no Paraná.

Labont (1989) realizou uma pesquisa sobre o uso de agrotóxicos entre os fazendeiros no Canadá e verificou que, no ano de 1983, houve 3.404 casos de intoxicação entre os trabalhadores rurais, sendo que 1.458 fazendeiros foram hospitalizados.

McConnel e Hruska (1993) relataram um aumento epidêmico de intoxicações por pesticidas em uma área da Nicarágua. Dos 548 casos identificados em 1987, cerca de $91 \%$ se deveram à exposição ocupacional, geralmente em pequenas propriedades rurais (menos de 140 hectares). Atribuem o aumento de casos à falta de proteção individual na aplicação manual dos produtos, à autorização local para uso de substâncias altamente tóxicas e de uso restrito em vários países, bem como à existência de subsídios agrícolas que encorajam o uso de agrotóxicos.

Garry (1994) estudou 1.000 aplicadores de agrotóxicos em Minnesota, nos Estados Unidos, e constatou que a diminuição da acetilcolinesterase era $20 \%$ mais freqüente nos aplicadores que pulverizavam os agrotóxicos em lugares fechados do que naqueles que o faziam em áreas abertas. Foi concluído nesse estudo que as doenças crônicas de pulmão também eram mais freqüentes nos aplicadores de agrotóxicos em lugares fechados.

Mwanthi (1993) analisou, entre 1987 e 1990, os padrões de manuseio de agrotóxicos e as respostas comunitárias no Quênia, África. Os dados levantados demonstraram que apesar dos seus conhecimentos limitados sobre segurança no manuseio e armazenamento, $100 \%$ dos entrevistados usavam os agrotóxicos de forma intensiva. Acredita o autor que a falta de consciência dos indivíduos e da comunidade em relação aos riscos associados ao uso destas substâncias foi o fator que contribuiu para o aparecimento dos casos de intoxicações relatados.

McDougall (1993) estudou o uso de agrotóxicos e a percepção dos riscos para a saúde em agricultores na Ilha de Santa Lúcia, no Caribe, onde 
SILVA, P.S.L. et al. Reflexão sobre o senso de percepção de risco no uso de agrotóxicos pelos pequenos agricultores no Assentamento Samba no município de Maragogi - Alagoas. PUBVET, Londrina, V. 5, N. 11, Ed. 158, Art. 1068, 2011.

observou que $60 \%$ dos entrevistados nunca usavam roupas de proteção e que $25 \%$ fumavam enquanto aplicavam os agrotóxicos.

Popper et al. (1993) analisaram o conhecimento dos riscos à saúde entre os fazendeiros e suas esposas na Guatemala, e identificaram que eles usavam produtos altamente tóxicos e que a dosagem dependia da quantidade de pragas sobre a terra e sobre as plantas. A maioria deles tinha um baixo conhecimento dos riscos de uso dos mesmos. A maior parte das donas de casa aplicava agrotóxicos para combater os piolhos em suas crianças, quando já tinha sido mencionado que esses produtos causavam problemas de saúde como náuseas, vertigem e dor de cabeça.

Stewart (1996) organizou uma pesquisa sobre as práticas do uso de agrotóxicos entre os trabalhadores rurais do Egito e observou que 58,2\% desses agricultores não usavam equipamento de proteção, que somente $7,7 \%$ dos fazendeiros usavam luvas e que $42,5 \%$ dos entrevistados lavavam a embalagem do produto e a reutilizavam.

Sartorato (1996) analisou os riscos da aplicação de agrotóxicos em dois assentamentos rurais e constatou que a caracterização dos assentamentos se reflete nas semelhanças e dessemelhanças existentes no processo produtivo e também nas "visões do mundo" dos trabalhadores que produzem com agrotóxicos (em São José da Boa Morte, Cachoeiras de Macacu, RJ) e daqueles que produzem sem agrotóxicos (Eldorado, Seropédica, RJ). Observou-se que os lavradores de Eldorado, do assentamento Casas Altas, possuíam mais conhecimento sobre os riscos dos agrotóxicos para a saúde humana e ambiental do que os de São José da Boa Morte, que os utilizavam intensamente e não os associavam ao aumento de pragas e à produtividade reduzida.

Tinoco-Ojanguren e Halperin (1998) observaram que no México os produtores rurais de subsistência apresentavam níveis menores de colinesterase sangüínea, indicando maior exposição aos inseticidas organofosforados do que os que adotavam outros sistemas de produção agrícola. 
SILVA, P.S.L. et al. Reflexão sobre o senso de percepção de risco no uso de agrotóxicos pelos pequenos agricultores no Assentamento Samba no município de Maragogi - Alagoas. PUBVET, Londrina, V. 5, N. 11, Ed. 158, Art. 1068, 2011.

Guillette et al. (1998) constataram uma redução na capacidade mental, bem como um incremento do comportamento agressivo de crianças mexicanas de 4 a 5 anos de idade expostas aos agrotóxicos, em áreas de uso intensivo desses produtos (mais que 45 aplicações anuais).

Araújo et al. (2000) estudaram as práticas de uso de agrotóxicos em plantadores de tomate de duas localidades do Estado de Pernambuco. Em uma das localidades, observaram que as embalagens vazias dos produtos não tinham um destino estabelecido previamente $(44,5 \%)$ : ou eram enterradas no próprio local (37\%) ou eram armazenadas para queima posterior $(18,5 \%)$. Na outra localidade, os autores constataram que 13,2\% dos agricultores já tinham sofrido algum tipo de intoxicação. Por outro lado, neste mesmo local, só 36\% dos entrevistados utilizaram o Receituário Agronômico; apenas 13\% receberam instruções sobre a utilização dos produtos e $64,2 \%$ informaram que não faziam uso de equipamentos de proteção individual.

Moreira et al. (2001), em uma avaliação integrada do regime de uso de agrotóxicos no município de Nova Friburgo, no Estado do Rio de Janeiro, estudaram um grupo de agricultores expostos a mais de 100 produtos (adultos e crianças). Notaram que $62,3 \%$ dos adultos e $38,6 \%$ das crianças não usavam equipamento de proteção e que $47,8 \%$ dos primeiros e $52 \%$ das crianças não haviam recebido nenhum tipo de treinamento para manipular agrotóxicos. O relato de aparecimento de sintomas após o processo de aplicação foi de $47,8 \%$ nos adultos e $34 \%$ nas crianças.

Oliveira-Silva et al. (2001) analisaram amostras sangüíneas de um grupo de 55 agricultores do município de Magé, no Estado do Rio de Janeiro. Utilizando métodos enzimáticos para detecção de intoxicações por agrotóxicos anticolinesterásicos, observaram que cerca de $45 \%$ apresentavam sinais de intoxicação, mais comuns em indivíduos com baixa escolaridade.

Trabalho de Gomide (2005) apresenta resultados de uma pesquisa desenvolvida com agricultores de dois municípios do sudeste do Piauí, que apontaram para uso de práticas defensivas tais como o consumo de bebida 
SILVA, P.S.L. et al. Reflexão sobre o senso de percepção de risco no uso de agrotóxicos pelos pequenos agricultores no Assentamento Samba no município de Maragogi - Alagoas. PUBVET, Londrina, V. 5, N. 11, Ed. 158, Art. 1068, 2011.

alcoólica, a sublocação do serviço aos mais jovens e a existência de um certo grau de compreensão do risco à saúde com a utilização dos agrotóxicos.

Segundo dados da pesquisa os agricultores têm um senso do perigo ao utilizarem agrotóxicos, embora não seguindo nenhuma recomendação preconizada nas bulas dos produtos. A adaptação ao perigo foi a pratica de terceirizar o serviço na medida em que o aplicador começa a apresentar sinais e sintomas de intoxicação repetitivos e maios ou menos prolongados que dificultam ou impossibilitem trabalhar. Os agrotóxicos são considerados como veneno (GOMIDE, 2005).

Trabalho concretizado por Castro e Confalonieri (2005) tendo por base levantamento efetuado junto a agricultores e autoridades de Cachoeiras de Macacu (RJ), acerca da percepção de risco e das práticas de uso dos agrotóxicos. A análise dos resultados demonstrou que $22,5 \%$ dos agricultores reportaram já terem sido intoxicados por agrotóxico, sendo o inseticida Decis 25 CE e o herbicida Gramoxone (ambos extremamente tóxicos) os mais utilizados na região. Verificou-se que $85 \%$ dos agricultores não utilizavam Equipamentos de Proteção Individual (EPI), que 27,5\% jogavam embalagens de agrotóxicos no rio ou no mato, que $60 \%$ de entrevistados nunca foram treinados para manusear agrotóxicos e que $85 \%$ disseram não precisar de receituário agronômico para comprá-los (CASTRO; CONFALONIERI, 2005).

Em relação à percepção do risco do uso de agrotóxicos Castro e Confalonieri (2005) identificaram três categorias: 70\% percebem, mas continuam usando; $27 \%$ não percebem o risco; $3 \%$ percebem e não utilizam mais. O entendimento é de que devido à natureza multifacetada do problema do uso abusivo de agrotóxicos no País, dos riscos para o meio ambiente e para a saúde humana por eles produzidos, apenas uma ação multissetorial de médio a longo prazo seria capaz de reduzir os impactos negativos destas substâncias (CASTRO; CONFALONIERI, 2005).

Os estudos de percepção de riscos surgem a partir da década de 1970/1980 como um importante contraponto à perspectiva utilitarista das análises técnicas de risco, baseada nos saberes das engenharias, toxicologia, 
SILVA, P.S.L. et al. Reflexão sobre o senso de percepção de risco no uso de agrotóxicos pelos pequenos agricultores no Assentamento Samba no município de Maragogi - Alagoas. PUBVET, Londrina, V. 5, N. 11, Ed. 158, Art. 1068, 2011.

economia e ciências atuariais, e que não contemplava as crenças, receios e inquietações das comunidades envolvidas (PERES; ROZEMBERG; LUCCA, 2005).

Conforme Peres, Rozemberg e Lucca (2005) os estudos emergem e se consolidam, em uma área do saber cientificamente organizada, com o intuito de desvelar as razões que acompanhavam as reações negativas do público leigo frente ao advento de uma nova tecnologia, mesmo que com o aval dos especialistas técnicos.

Os principais aspectos relacionados à percepção de riscos no trabalho rural são a minimização de riscos/negação do perigo e o desenvolvimento de estratégias defensivas - individuais e coletivas - pelos trabalhadores rurais, aspectos estes que encontram seus determinantes na organização do trabalho e na ação técnica voltada à extensão rural (PERES; ROZEMBERG; LUCCA, 2005).

Fonseca et al. (2007) desenvolveram trabalho sobre os riscos relacionados ao uso de agrotóxicos na produção de flores da região de Barbacena, Minas Gerais e, nele, foram investigadas especificamente as representações e ações associadas ao manejo do agrotóxico nessa população. A análise dos dados de campo indicam que os trabalhadores enfrentam duas realidades: a necessidade do agrotóxico e o sofrimento gerado pelo seu manejo.

Foi constatado que não há uma relação direta entre o conhecimento dos riscos e perigos associados ao agrotóxico. A distância é preenchida por crenças que constituem o eixo organizador das ações e tais crenças reinterpretam a informação e o risco, influenciam o comportamento e viabilizam a movimentação destes trabalhadores entre estas realidades paradoxais e sua convivência com o agrotóxico. Contudo, a resignificação do risco pode implicar numa valorização positiva de comportamentos potencialmente danosos (FONSECA et al., 2007).

O estudo realizado por Veiga (2007) apresentou análise sobre a relação inversa entre eficiência econômica e justiça socioambiental na utilização de 
SILVA, P.S.L. et al. Reflexão sobre o senso de percepção de risco no uso de agrotóxicos pelos pequenos agricultores no Assentamento Samba no município de Maragogi - Alagoas. PUBVET, Londrina, V. 5, N. 11, Ed. 158, Art. 1068, 2011.

agrotóxicos. Em seu trabalho Veiga constatou que a utilização de agrotóxicos tenderia a maximizar a eficiência econômica através de ganhos de produtividade. Por outro lado, poderia agravar a injustiça socioambiental. Analisando o impacto de instrumentos regulatórios no controle da utilização e do manejo de agrotóxicos ele observou que uma legislação que reduza compulsoriamente a utilização de agrotóxicos poderia agravar diversos problemas socioeconômicos, especialmente em pequenas comunidades rurais.

Com base no estudo concluiu-se que eventuais restrições na utilização de agrotóxicos em sistemas produtivos que dependam dessas matérias-primas para sustentar sua economia poderia ser bastante prejudicial. Em relação à necessidade de intervenção estatal para regular a utilização de agrotóxicos, a conclusão é de que a questão não deveria ser sobre a necessidade ou não de legislação, mas sim como deve ser a forma dessa intervenção (VEIGA, 2007)

Em estudo realizado com agricultores de Culturama, Mato Grosso do Sul, em 2005, por Recena e Caldas (2008), foi avaliada a percepção de risco, práticas e atitudes no uso de agrotóxicos por agricultores sendo constatado que os agricultores se mostraram cientes dos riscos de exposição direta e indireta ao utilizar agrotóxicos; muitos se mostraram preocupados com a contaminação potencial do meio ambiente.

As informações que os agricultores tinham sobre agrotóxicos eram restritas principalmente à dosagem do produto, cuja principal fonte eram os revendedores. Os agricultores reclamaram do tamanho das letras e da linguagem técnica do rótulo e da bula, mas muitos souberam interpretar os pictogramas e o código de cor de toxicidade presentes neles (RECENA; CALDAS, 2008).

Em seu trabalho Recena e Caldas (2008) concluem que os agricultores nem sempre transformam sua percepção de risco e suas experiências pessoais em atitudes e práticas mais seguras no uso de agrotóxicos, como o uso adequado de equipamentos de proteção individual.

Para elas os agricultores envolvidos na pesquisa sentem-se indefesos diante das situações de risco, principalmente devido aos fatores ambientais 
SILVA, P.S.L. et al. Reflexão sobre o senso de percepção de risco no uso de agrotóxicos pelos pequenos agricultores no Assentamento Samba no município de Maragogi - Alagoas. PUBVET, Londrina, V. 5, N. 11, Ed. 158, Art. 1068, 2011.

não controláveis e à vulnerabilidade econômica. A recomendação é de que há necessidade de implantação de programas governamentais de extensão agrícola que enfatizem técnicas alternativas de manejo de pragas e práticas seguras de uso de agrotóxicos, direcionados a essa população (RECENA; CALDAS, 2008).

Em trabalho concretizado por Alves et al. (2008) objetivando conhecer o cenário no qual os trabalhadores da cultura de tomate em Goiás estão inseridos e com base em entrevista, questionário proposto aos trabalhadores que manipulam os agrotóxicos e a técnica da observação livre, foi constatado que eles estão constantemente expostos aos agrotóxicos e há uma falta de preparo para a manipulação dessas substâncias.

Alves et al. (2008) concluíram que a aplicação sistemática de produtos químicos pelos produtores estudados, associada aos equipamentos e tecnologias empregados na sua aplicação, propiciam aos trabalhadores (que apresentam baixo nível de escolaridade) uma exposição constante aos agrotóxicos.

Na prática não é observado o horário da aplicação, do intervalo de reentrada e o uso inadequado de EPI's evidenciando, obviamente, a falta de preparo dos trabalhadores para a manipulação dos agrotóxicos. Eles reconhecem os riscos a que estão expostos, mas não mudam a atitude (ALVES et al., 2008).

Conforme Bedor et al. (2009) a determinação de situações de riscos na população que faz uso de agrotóxico é complexa. Em trabalho realizado com produtores rurais que trabalham com fruticultura no Vale do São Francisco foi verificado que os trabalhadores rurais da região têm em sua maioria baixo grau de escolaridade, sendo esta uma importante vulnerabilidade para compreensão da rotulagem dos agrotóxicos e sua implicação toxicológica e ambiental. Eles observaram que uso indiscriminado de agrotóxicos em condições inseguras de trabalho que comprometem a saúde dos expostos e que a sintomatologia sugestiva de intoxicação por agrotóxicos aponta para quadros relacionados com exposição à organofosforados, carbamatos e 
SILVA, P.S.L. et al. Reflexão sobre o senso de percepção de risco no uso de agrotóxicos pelos pequenos agricultores no Assentamento Samba no município de Maragogi - Alagoas. PUBVET, Londrina, V. 5, N. 11, Ed. 158, Art. 1068, 2011.

piretróides, em congruência com os biocidas utilizados na fruticultura. Foi levantado que $7 \%$ da população estudada por eles referiram ter sofrido pelo menos um caso de intoxicação no decorrer da vida.

O trabalho de Bedor et al. (2009) revela que a assistência técnica relacionada com o manejo de agrotóxicos é precária não se observando ações de proteção no âmbito da saúde, do trabalho, da previdência ou do ambiente. $O$ entendimento é de que tais vulnerabilidades institucionais confirmam as relacionadas com 0 modelo tecnológico que objetiva meramente a produtividade e o rendimento financeiro.

\section{MATERIAL E METODOS}

O município de Maragogi está localizado na porção norte do Estado de Alagoas, ocupando uma superfície de $33 \mathrm{~km}^{2}$, limita-se ao norte com a cidade de São José da Coroa Grande, Estado de Pernambuco, ao sul com a cidade de japaratinga, a leste com a cidade de Jacuipe, a oeste com o oceano atlântico. Possui uma população de 21.832 habitantes, sendo 8.930 habitantes na zona rural $^{1}$.

No tocante aos recursos naturais, Maragogi dispõe de um grande potencial de recursos hídricos, compreendendo as praias, os risos e os manguezais, sendo considerado o segundo maior pólo turístico do Estado de Alagoas, perdendo somente para a capital Maceió. Tem clima favorável para o desenvolvimento de diversas culturas agrícolas, além de terras férteis.

O município de Maragogi é considerado o de maior área de assentamento do Estado de Alagoas $^{2}$, uma vez que 1/3 de suas terras passou a pertencer aos assentamentos, com 1.063 famílias assentadas, sem formação escolar e agrícola para trabalhar na terra. Em sua maioria os assentados são provenientes das atividades canavieiras ligadas as usinas da região.

\footnotetext{
${ }^{1}$ Dados do censo demográfico de 2000

${ }^{2}$ Dado do Plano de Desenvolvimento do Assentamento Samba de 2004
} 
SILVA, P.S.L. et al. Reflexão sobre o senso de percepção de risco no uso de agrotóxicos pelos pequenos agricultores no Assentamento Samba no município de Maragogi - Alagoas. PUBVET, Londrina, V. 5, N. 11, Ed. 158, Art. 1068, 2011.

A localidade de estudo foi o Assentamento Samba, localizado na zona rural do município de Maragogi. Originalmente a área do projeto assentamento samba pertencia à usina Central Barreiros. Ao longo dos últimos anos da década de oitenta esta usina, em função de problemas administrativos internos e da economia nacional à época, entrou em estado de falência gerando o abandono dessa e de várias fazendas do grupo. Ao perceber essa situação, movimentaram-se por um lado a prefeitura municipal de Maragogi e, por outro, os movimentos sociais ligados aos trabalhadores sem terra: Movimento dos Trabalhadores Rurais Sem Terra (MST) e Movimento dos Trabalhadores (MT), com o mesmo objetivo que era de utilizar as terras abandonadas para $p$ assentamento de famílias da região que haviam perdido o emprego de cortadores de cana e de outras que não possuíam terras para plantar e/ou criar. O Assentamento possui 129 famílias, uma área médias de parcela de 6,212 ha.

Foi utilizada como metodologia a pesquisa quantitativa, indo a busca dos dados subjetivos da percepção que a comunidade pesquisada tem sobre a prática do uso de agrotóxicos.

A pesquisa foi realizada com os agricultores através de questionários. Foram distribuídos 30 questionários. A definição do tamanho da amostra foi fundamentada na Teoria do Limite Central, tendo em vista as características semelhantes dos pequenos agricultores do assentamento alvo da pesquisa.

O trabalho de campo foi realizado no período entre maio e junho de 2010. As visitas foram feitas semanalmente junto com a equipe da Cooperativa Agrícola de Assistência Técnica e Serviços (COOATES).

Foram realizadas 20 visitas ao campo. O número de entrevistas alternou entre o mínimo de uma até cinco em uma mesma visita. A duração das entrevistas variava de acordo com os agricultores, podendo durar de meia hora até 3 horas. Durante as visitas aos produtores rurais, o critério de escolha dos pesquisados foi aleatório não importando o sexo, mas um representante, agricultor ou agricultora, que se dispusesse a responder o questionário, no momento da entrevista, sobre a prática de uso dos agrotóxicos. 
SILVA, P.S.L. et al. Reflexão sobre o senso de percepção de risco no uso de agrotóxicos pelos pequenos agricultores no Assentamento Samba no município de Maragogi - Alagoas. PUBVET, Londrina, V. 5, N. 11, Ed. 158, Art. 1068, 2011.

\section{RESULTADOS DA PESQUISA DE CAMPO}

A região é constituída por pequenos produtores dependente exclusivamente da agricultura para sustentar seus familiares, em sua grande maioria localizada na faixa etária entre 30 e 50 anos, conforme podemos observar na figura 1.

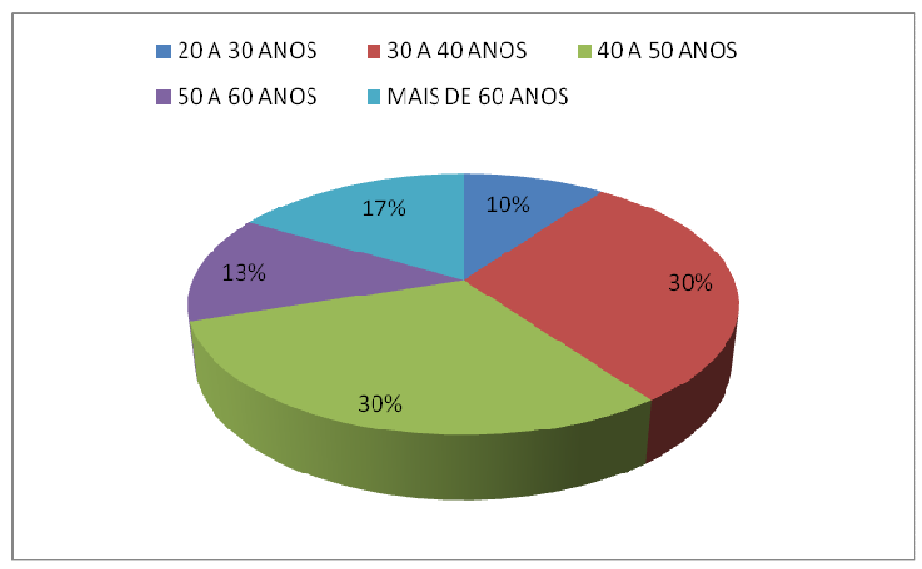

Figura 1 - Faixa etária dos entrevistados

Dados da figura 2 evidenciam o pouco nível de escolaridade dos entrevistados, que pode ser observado como um limitador para aferir o senso de percepção de risco quando do uso de agrotóxicos

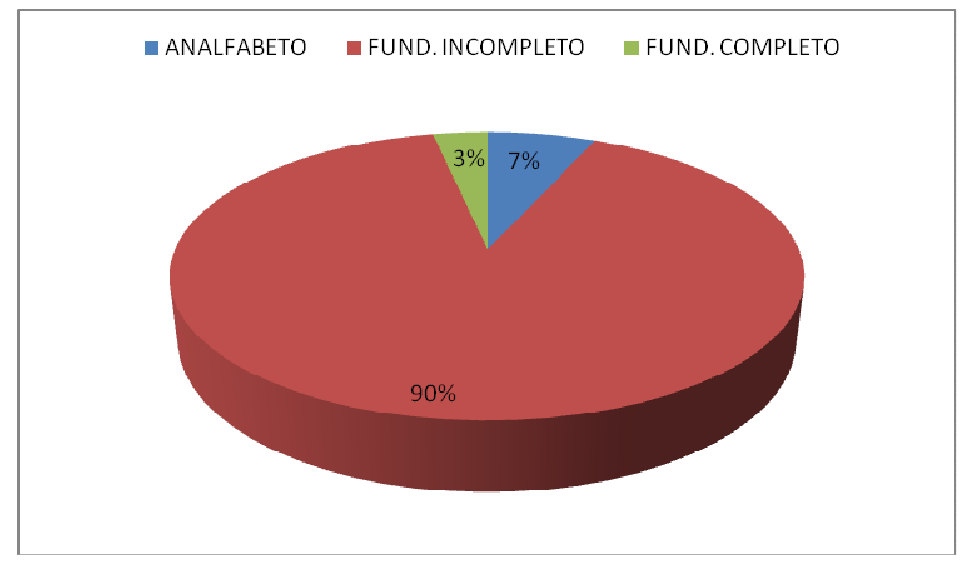

Figura 2 - Grau de escolaridade dos entrevistados 
SILVA, P.S.L. et al. Reflexão sobre o senso de percepção de risco no uso de agrotóxicos pelos pequenos agricultores no Assentamento Samba no município de Maragogi - Alagoas. PUBVET, Londrina, V. 5, N. 11, Ed. 158, Art. 1068, 2011.

Quanto às culturas agrícolas desenvolvidas pelos pequenos agricultores, faz-se necessário mencionar novamente que eles dependem tão somente da agricultura para garantir a sustentação de suas famílias, para tanto cultivam basicamente frutíferas e gramíneas, assim distribuídos, conforme o contido na figura 3.

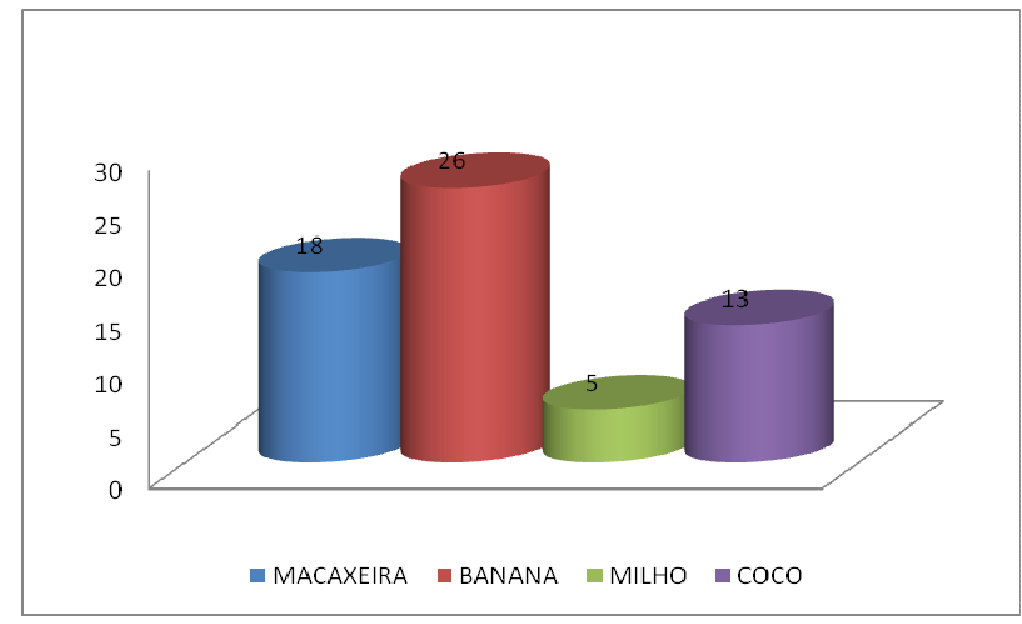

Figura 3 - Culturas cultivadas pelos entrevistados

Quanto à necessidade de utilizar agrotóxicos $96,7 \%$ responderam que já precisaram e fazem uso de algum tipo de agrotóxicos, apenas 3\% dos entrevistados informaram que cultivam de forma agroecológica. Os motivos que levam esses pequenos agricultores a fazer uso de agrotóxicos constam na tabela 1.

Tabela 1 - Motivos que levam os agricultores a utilizar agrotóxicos

\begin{tabular}{l|c}
\hline \multicolumn{1}{c|}{ Motivos } & Percentual (\%) \\
\hline Controle de Pragas & 53,3 \\
Falta de recursos financeiros para mão & 33,3 \\
de obra & \\
Aumento da produção & 6,7
\end{tabular}


SILVA, P.S.L. et al. Reflexão sobre o senso de percepção de risco no uso de agrotóxicos pelos pequenos agricultores no Assentamento Samba no município de Maragogi - Alagoas. PUBVET, Londrina, V. 5, N. 11, Ed. 158, Art. 1068, 2011.

Quanto aos agrotóxicos que fazem ou já fizeram uso, foram obtidos os dados constantes na figura 4. Observa-se claramente que eles usam várias formulações de agrotóxicos, sem critérios.

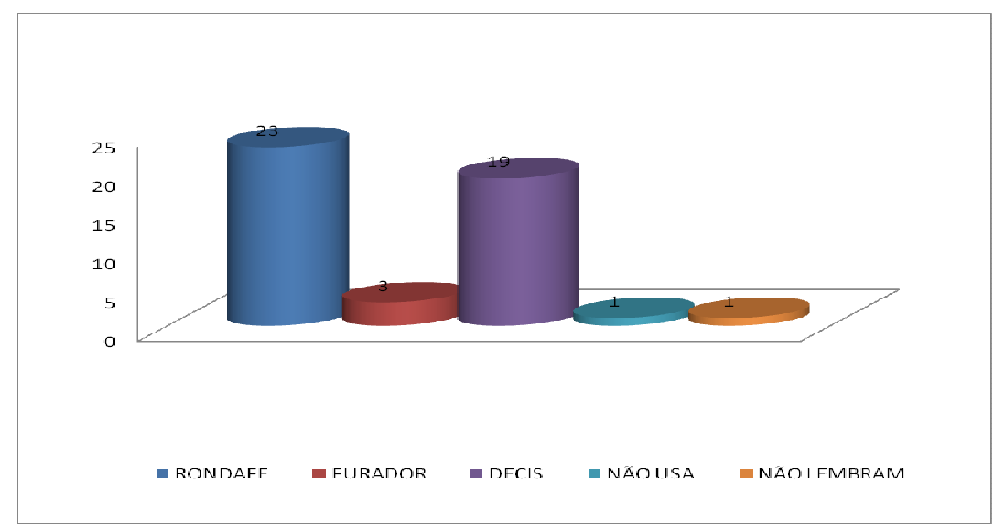

Figura 4 - Tipos de Agrotóxico utilizado pelos entrevistados

$\mathrm{Na}$ figura 5 observa-se que os entrevistados cultivam mais de uma cultura agrícola em sua propriedade e na opinião dos entrevistados essas seriam as culturas que mais necessitam de agrotóxicos.

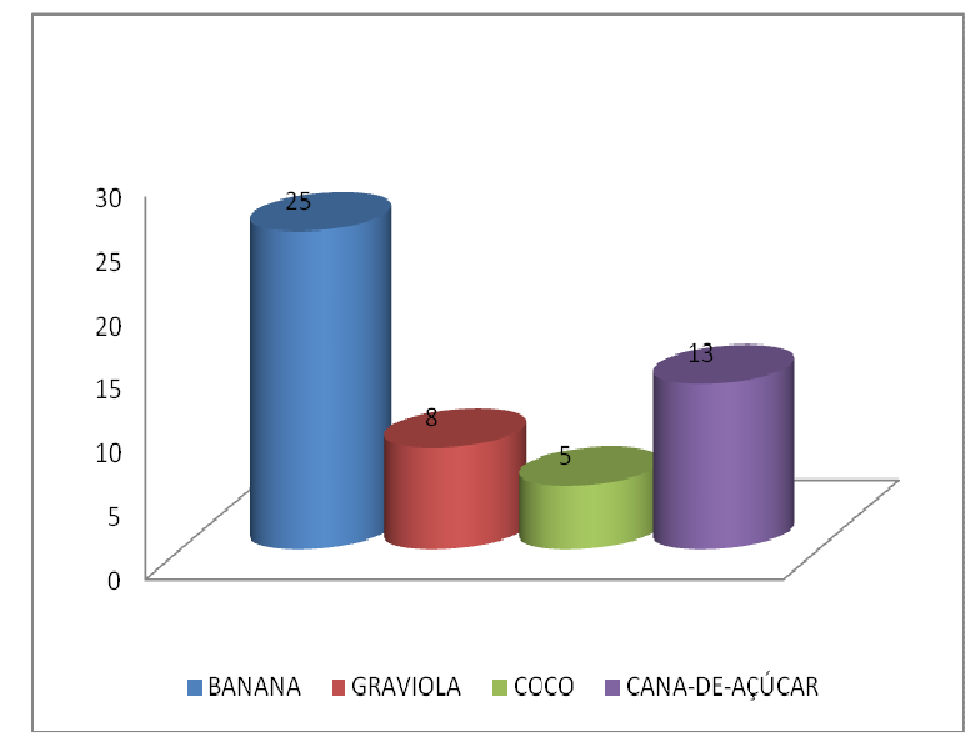

Figura 5 - Culturas que mais necessitam de agrotóxicos na opinião dos entrevistados 
SILVA, P.S.L. et al. Reflexão sobre o senso de percepção de risco no uso de agrotóxicos pelos pequenos agricultores no Assentamento Samba no município de Maragogi - Alagoas. PUBVET, Londrina, V. 5, N. 11, Ed. 158, Art. 1068, 2011.

Com relação aos cuidados a serem tomados quando do uso de agrotóxicos foram obtidos os dados constantes na figura 6 .

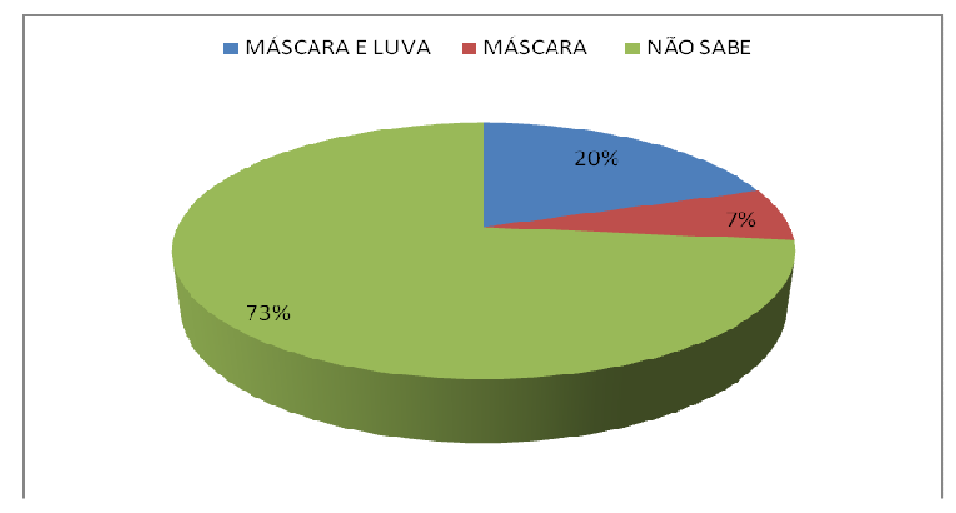

Figura 6 - Cuidados no uso de agrotóxicos na opinião dos entrevistados

Os dados obtidos evidenciam claramente que não houve qualquer treinamento quanto ao uso de agrotóxicos para esses pequenos produtores rurais, corroborando com os dados obtidos na figura 4 , com relação ao tipo a ser utilizado.

Dados da figura 7 vêm ratificar que os entrevistados, em sua grande maioria, não tiveram nenhum tipo de instrução com relação ao uso de agrotóxicos.

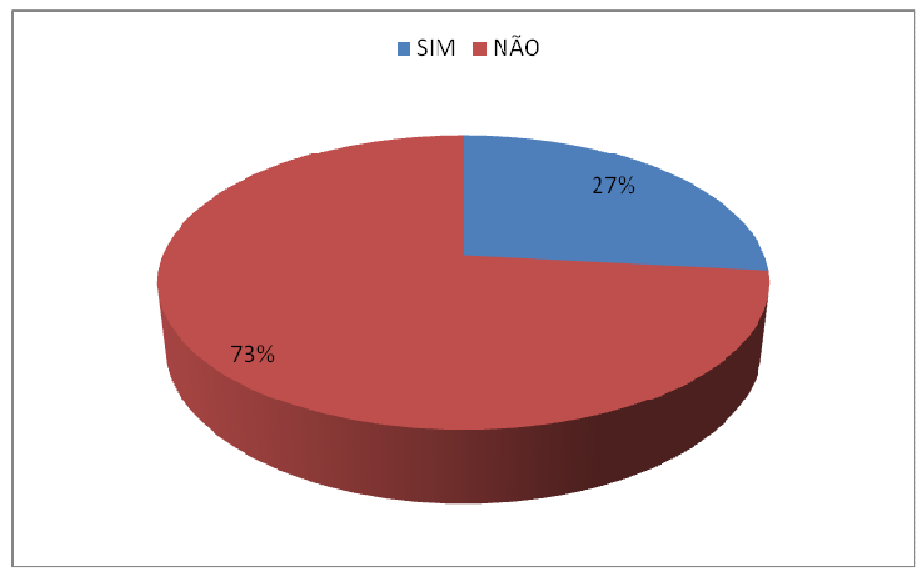

Figura 7 - Se o entrevistado recebeu alguma instrução no uso de agrotóxicos 
SILVA, P.S.L. et al. Reflexão sobre o senso de percepção de risco no uso de agrotóxicos pelos pequenos agricultores no Assentamento Samba no município de Maragogi - Alagoas. PUBVET, Londrina, V. 5, N. 11, Ed. 158, Art. 1068, 2011.

Conforme se observa a maioria dos entrevistados não tem Idéia do material que manipulam diariamente, evidenciando o baixo senso de percepção de risco.

Quando questionados se já tiveram algum tipo de instrução do que fazer com as embalagens usadas de agrotóxicos, apenas 10\%, aparentemente, tiveram algum tipo de instrução (figura 8).

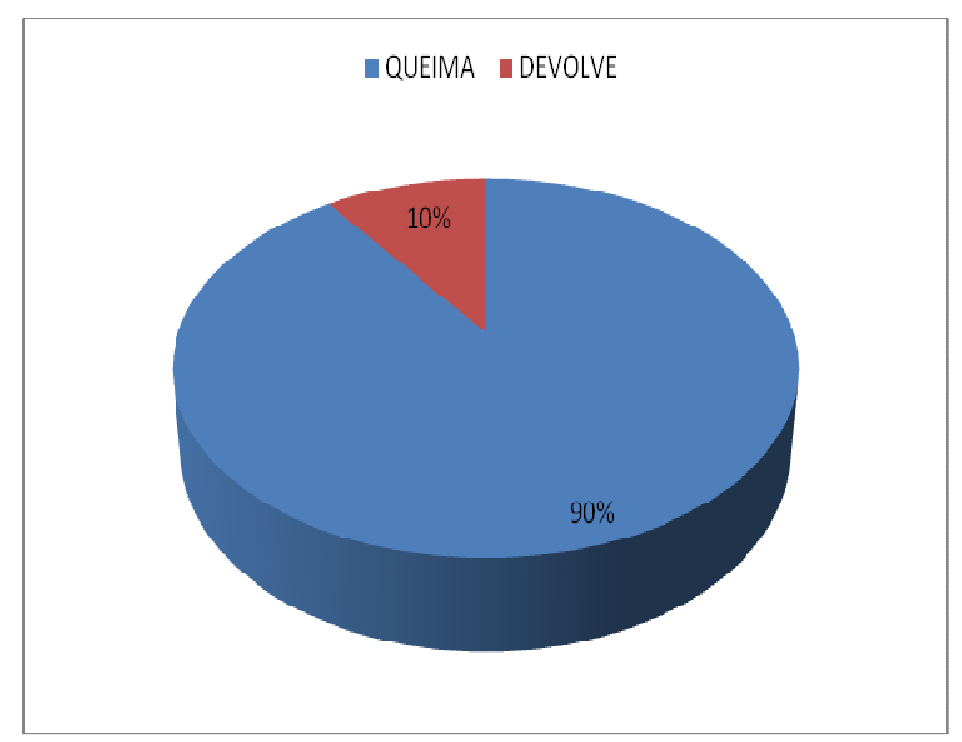

Figura 8 - Destino dado às embalagens de agrotóxicos usadas

Quando questionados se conhecem alguém que foi intoxicado por algum agrotóxico, 76,7\% responderam que não conhecem ninguém que tenha sido intoxicado por algum agrotóxico e 23,3 \% mencionaram que conhecem alguém que já foi vitima de intoxicação por agrotóxicos.

Quando questionados sobre o motivo principal da intoxicação a maioria não soube informar (figura 9). 
SILVA, P.S.L. et al. Reflexão sobre o senso de percepção de risco no uso de agrotóxicos pelos pequenos agricultores no Assentamento Samba no município de Maragogi - Alagoas. PUBVET, Londrina, V. 5, N. 11, Ed. 158, Art. 1068, 2011.

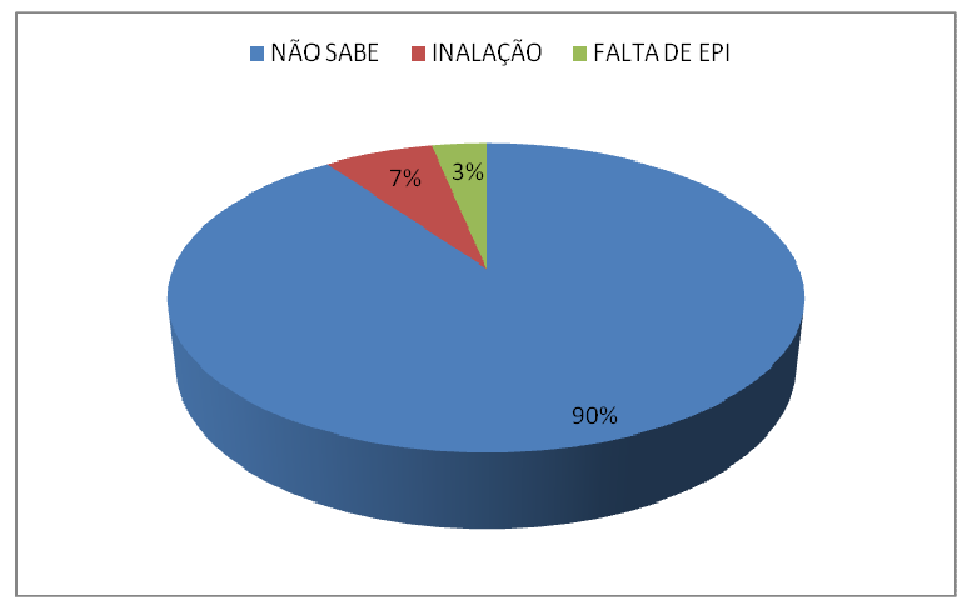

Figura 9 - Principal motivo das intoxicações na opinião dos entrevistados

Finalmente, na figura 10, os entrevistados mencionaram o que poderia ser feito para diminuir os casos de intoxicação.

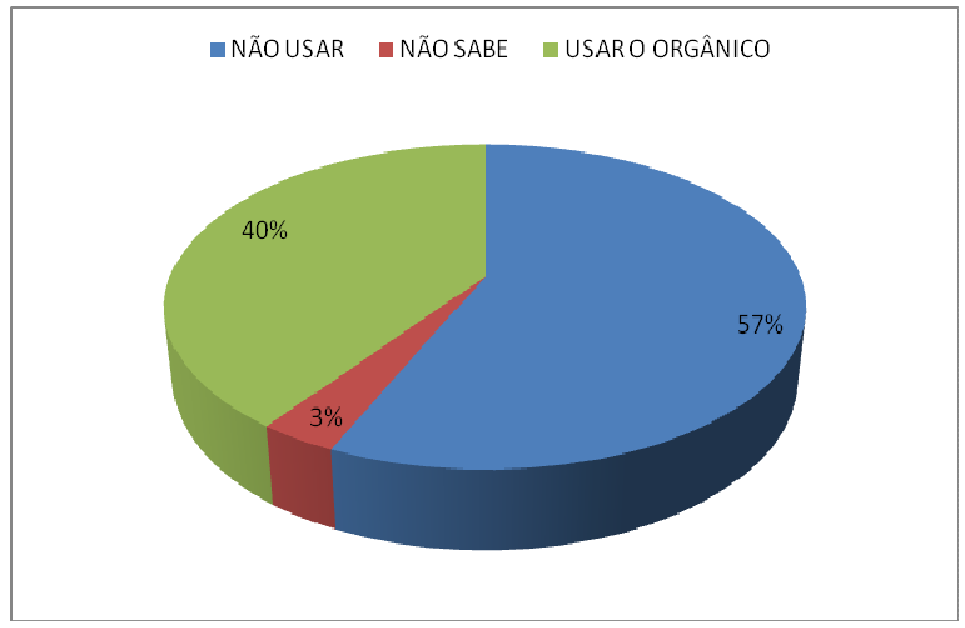

Figura 10 - O que fazer para diminuir os casos de intoxicação na opinião dos entrevistados

Percebe-se que os entrevistados apesar de não mencionarem qualquer alusão a treinamento ou instrução no uso de agrotóxicos para diminuir os casos de intoxicação, opinam por métodos alternativos, levando acreditar que de alguma forma, mesmo que empiricamente, tem relativa consciência do risco, mas paradoxalmente não conhecem os produtos que necessitam manipular. 
SILVA, P.S.L. et al. Reflexão sobre o senso de percepção de risco no uso de agrotóxicos pelos pequenos agricultores no Assentamento Samba no município de Maragogi - Alagoas. PUBVET, Londrina, V. 5, N. 11, Ed. 158, Art. 1068, 2011.

\section{CONSIDERAÇÕES FINAIS}

Os pequenos agricultores do assentamento Samba reconheceram a possibilidade de intoxicação após o uso inadequado de agrotóxicos no campo. Porém, eles nem sempre transformam seus conhecimentos e suas experiências pessoais em atitudes e práticas mais seguras, como o uso adequado de EPI. Dentre as razões para essa dissociação estava o sentimento de impotência diante das situações de risco, principalmente, a vulnerabilidade econômica dos pequenos agricultores do assentamento samba.

Uma possível limitação dos resultados obtidos está ligada a composição do grupo focal, os entrevistados eram indivíduos cujas parcelas eram próximas uma das outras. Krueger (1994) enfatiza que grupos focais formados por indivíduos que se conhecem e trabalham próximos tem uma dinâmica préexistente própria e as discussões no grupo podem ser influenciadas pelas relações inter-pessoais, levar à inibição de observações negativas e sofrer influência de hierarquia formais e informais. Os resultados do presente estudo podem ser extrapolados para outros assentamentos, já que foram obtidos a partir de número adequado de grupos focais homogêneos, compostos por indivíduos selecionados aleatoriamente.

Os resultados encontrados mostram a necessidade de maior atuação do poder público com a população do Assentamento Samba. Isso pode ser feito por meio de programas de extensão agrícola, fornecendo assistência técnica intensiva e de qualidade na região, de maneira a criar vínculo de confiança entre técnicos e agricultores. Destarte, necessário se faz que o corpo técnico responsável enfatize as questões de segurança no uso de agrotóxicos e proponha métodos alternativos de controle de pragas.

\section{REFERÊNCIAS BIBLIOGRÁFICAS}

ALVES, Sueli Martins Freitas; FERNANDES, Paulo Marçal; MARIN, Joel Orlando Bevilaqua. Condições de trabalho associadas ao uso de agrotóxicos na cultura de tomate de mesa em Goiás. Ciênc. agrotec., [online]. vol.32, n.6, pp. 1737-1742. 2008. ISSN 1413-7054. 
SILVA, P.S.L. et al. Reflexão sobre o senso de percepção de risco no uso de agrotóxicos pelos pequenos agricultores no Assentamento Samba no município de Maragogi - Alagoas. PUBVET, Londrina, V. 5, N. 11, Ed. 158, Art. 1068, 2011.

ANVISA. Programa de Análise de Resíduos de Agrotóxicos em Alimentos: relatório anual 04/06/2001-30/06/2002. Brasília: Agência Nacional de Vigilância Sanitária. 2002.

ARAÚJO, A. C. P..; NOGUEIRA, D. P.; AUGUSTO, L. G. S. Impacto dos praguicidas na saúde: estudo da cultura de tomate. Revista de Saúde Pública, São Paulo, v. 34, n.3, p. 309-313, 2000.

BEDOR, Cheila Nataly Galindo et al. Vulnerabilidades e situações de riscos relacionados ao uso de agrotóxicos na fruticultura irrigada. Rev. bras. epidemiol., [online] vol.12, n.1, pp. 39-49. 2009ISSN 1415-790X.

BOTOLETTO, ME. Tóxicos, civilização e saúde. Contribuição à análise dos sistemas de informações tóxico-farmacológicas no Brasil. Fundação Oswaldo Cruz, Rio de Janeiro. 1990.

BRASIL. Ministério da Saúde. Secretaria de Vigilância Sanitária. 1997. Manual de vigilância da saúde de populações. Brasília: Organização Pan-Americana da Saúde, 1997.

CASTELO BRANCO, M. Avaliação do conhecimento do rótulo dos insenticidas por agricultores em uma área agrícola do Distrito Federal. Hortic Bras., 21(3):570-3. 2003.

CASTRO, Jane S. Maia; CONFALONIERI, Ulisses. Uso de agrotóxicos no Município de Cachoeiras de Macacu (RJ). Ciênc. saúde coletiva, [online] vol.10, n.2, pp. 473-482. 2005. ISSN 1413-8123.

CHISTÉ AMD, Co WL. Percepção ambiental de uma comunidade pomerana em relação ao uso de agrotóxicos. Natureza on line, 1:7-11. 2003.

CORIN, E.; UCHÔA, E.; BIBEAU, G; KOUMARE, B. Psicopathologie Africaine, 24,2:183-190. 1992.

DELGADO, IF; PAUMGARTTEN, FJR. Intoxicações e uso de pesticidas por agricultores do Município de Paty do Alferes, Rio de Janeiro, Brasil. Cad Saúde Pública, 20(1):180-6. 2004.

DOUGLAS, M; WILDAVSKY, A. Risk and culture: an essay on selection of technological and environmental dangers. Berkerley: University of California Press, 1992.

FINUCCANE, M L; SLOVIC, P; MERTZ, C K; FLYAN, J; SATTERFIELD, TA. Gender, race, perceived risk: the "white male" effect. Health, Risk \& Society, 2, 159-172. 2000.

FIRMO, JOA; LIMA-COSTA, MF; UCHÔA, E. Projeto Bambuí: maneiras de pensar e agir de idosos hipertensos. Cad Saúde Pública, 20(4):1029-1040. 2004.

FONSECA, Maria das Graças Uchoa; PERES, Frederico; FIRMO, Josélia Oliveira Araújo; UCHOA, Elizabeth. Percepção de risco: maneiras de pensar e agir no manejo de agrotóxicos. Ciênc. saúde coletiva, [online] vol.12, n.1, pp. 39-50. 2007. ISSN 1413-8123.

GOMIDE, Márcia. Agrotóxico: que nome dar?. Ciênc. saúde coletiva, [online] vol.10, n.4, pp. 1047-1054. 2005. ISSN 1413-8123.

HORLICK-JONES, T; SIME, J.; PIDGEON, N. "The social dynamics of environmental risk perception: implications for risk communication rescarch and practice". In: The social amplification of risk. Cambridge: Cambridg University Press; 2003. P.262-285.

HOUAISS, A. Dicionário Houaiss da língua portuguesa. Rio de Janeiro: Objetiva, 2001.

INSTITUTO BRASILEIRO DE GEOGRAFIA E ESTATÍSTICA (IBGE). Disponível em: <www.ibge.gov.br>. Acessado em: 5.abr.2010.

IGBEDIOH, SO. Effects of agricultural pesticides on humans, animal and higher plants in developing countries. Archives of environmental Health, 46(4): 218-223. 1991.

KEIFER C, JEYARATNAM J. Pesticide hazards in developing countries. Sci Total Environ., 188(supl 1):S78-85. 2000. 
SILVA, P.S.L. et al. Reflexão sobre o senso de percepção de risco no uso de agrotóxicos pelos pequenos agricultores no Assentamento Samba no município de Maragogi - Alagoas. PUBVET, Londrina, V. 5, N. 11, Ed. 158, Art. 1068, 2011.

$\mathrm{KOH}$, Jeyaratnam j. Pesticide hazards in developing countries. Sci Total Environ, 188(Supl 1):578-85. 1996,

KONRADSEN, F; VAN DER HOEK, W; COLE, DC; HUTCHINSON, G; DAISLEY, H; SINGH, S; EDDLESTON, M. Reducing acute poisoning in developing countries - options for restricting the availability of pesticides. Toxicology., 192(2-3):249-61. 2003.

KOUABENAM, DR. Beliefs and the perception of risks and accidents. Risk Analysis, 18(03):243-252. 2000.

KRUEGER, RA. Focus group: a practical guide for applied research. Thousand Oaks: Sage; 1994.

LABONT, RN. Pesticides and healthy public policy. Canadian Journal of Public Health 80:231-242. A. M. J. Public Health, 83(11):1.559-565. 1989.

LEVIGARD, YE. A interpretação dos profissionais de saúde acerca das queixas do nervoso no meio rural: uma aproximação ao problema das intoxicações por agrotóxicos [dissertação]. Rio de Janeiro (RJ): Escola Nacional de Saúde Pública; 2001.

LOYOLA FILHO, A; LIMA-COSTA, F; UCHÔA, E. Projeto Bambuí: Uso de medicamentos decorrentes da exposição a agrotóxicos. Cad Saúde Pública, 20(6): 161-165. 2004.

MCDOUGALL, R; HRUSKA, AJ. An epidemic of pesticide poisoning in Nicaragua: implications for prevention in developing countries. 1993.

OLIVEIRA-SILVA, J]; MEYERA, A. O sistema de notificação das intoxicações: o fluxograma de joeira. In: Peres F; Moreira, JC. (organizadores). É veneno ou é remédio? Agrotóxicos, saúde e meio ambiente. Rio de Janeiro: Fiocruz, 2003. p.317-26.

PERES, F; ROZEMBERG, B; LUCCA, SR. Percepção de riscos no trabalho rural em uma região agrícola do Estado do Rio de Janeiro, Brasil: agrotóxicos, saúde e ambiente. Cad Saúde Pública, 21(6):1836-44. 2003.

PERES, Frederico; ROZEMBERG, Brani; LUCCA, Sérgio Roberto de. Percepção de riscos no trabalho rural em uma região agrícola do Estado do Rio de Janeiro, Brasil: agrotóxicos, saúde e ambiente. Cad. Saúde Pública, [online] vol.21, n.6, pp. 1836-1844. 2005. ISSN 0102-311X.

PERES, DX; CALDAS, ED; RECENA, MCP. Intoxicações provocadas por agrotóxicos de uso agrícola na microrregião de Dourados, Mato Grosso do Sul, no Brasil, no período de 1992 a 2002. Cad Saúde Pública, 21:804-814. 2005.

RECENA, Maria Celina Piazza; CALDAS, Eloisa Dutra. Percepção de risco, atitudes e práticas no uso de agrotóxicos entre agricultores de Culturama, MS. Rev. Saúde Pública, [online] vol.42, n.2, pp. 294-301. 2008. ISSN 0034-8910.

RECENA, MC; CALDAS, ED; PIRES, DX; PONTES, ER. Pesticides Exposure in Culturama/Brasil Knowledge, atitudes and pesticides. Environ Res.,102(2):230-6. 2006.

ROZEMBERG, B. O consumo de calmantes e o "problema de nervos" entre lavadoures. Revista de Saúde Pública, 2(4):300-308. 1994.

SIQUEIRA, ML; JACOB, A; CANHETE, RL. Diagnóstico dos problemas ecotoxicológicos causados pelo uso de defensivos agrícolas no Estado do Paraná. Revista Brasileira de Saúde Ocupacional. 11(44):7-17. 1983.

SLOVIC, P. The perception of risk. London: Earthscan Publications Ltd; 2000.

TRAPÉ, AZ. O caso dos agrotóxicos, PP. 565-593. In Rocha et al. Isto é trabalho de gente? Vida, doença e trabalho no Brasil. Vozes, Petrópolis, 1983.

TUCKER, M; NAPIER, TL. Determinants of perceived agricultural chemical risk in three watersheds in the Midwestern United States. J Rural Stud. 17(2):219-33. 2001. 
SILVA, P.S.L. et al. Reflexão sobre o senso de percepção de risco no uso de agrotóxicos pelos pequenos agricultores no Assentamento Samba no município de Maragogi - Alagoas. PUBVET, Londrina, V. 5, N. 11, Ed. 158, Art. 1068, 2011.

UCHÔA, E. Epidemiologia e antropologia. Contribuições para uma abordagem dos aspectos transculturais da depressão. In: Canesqui, AM, organizador. Ciências Sociais e Saúde. São Paulo: Editora Hucitec; Rio de Janeiro: Abrasco; 1997, p. 87-109.

VEIGA, Marcelo Motta. Agrotóxicos: eficiência econômica e injustiça socioambiental. Ciênc. saúde coletiva, [online] vol.12, n.1, pp. 145-152. 2007. ISSN 1413-8123.

WEJNERT, B. Integrating models of diffusion of innovation: a conceptual framework. Annual Review of sociology, 8:297-300. 2002.

YATES, F.; STONE, E. The Risk Construct. In: Yates F. organizador. Risk-taking behaviour, Chichest: Wiley, 1992. 